\title{
Comparison of local control and survival outcomes between surgical and non-surgical local therapy on pelvic Ewing's sarcoma patients: a meta-analysis
}

\author{
Xianbiao Xie ${ }^{1,2 \#}$, Ziliang Zeng ${ }^{1,2 \#}$, Hao Yao ${ }^{1}$, Qinglin Jin ${ }^{1,2}$, Yiying Bian ${ }^{1,2}$, Dongming Lv ${ }^{1,2}$, Jian Tu ${ }^{1,2}$, \\ Bo Wang ${ }^{1,2}$, Lili Wen ${ }^{3}$, Jingnan Shen ${ }^{1,2}$ \\ ${ }^{1}$ Department of Musculoskeletal Oncology Center, The First Affiliated Hospital of Sun Yat-Sen University, Guangzhou, China; ${ }^{2}$ Guangdong \\ Provincial Key Laboratory of Orthopedics and Traumatology, Guangzhou, China; ${ }^{3}$ Department of Anesthesiology, State Key Laboratory of \\ Oncology in South China, Sun, Yat-Sen University Cancer Center, Guangzhou, China \\ Contributions: (I) Conception and design: X Xie, Z Zeng; (II) Administrative support: L Wen, J Shen; (III) Provision of study materials or patients: \\ H Yao, Q Jin; (IV) Collection and assembly of data: Y Bian, D Lv; (V) Data analysis and interpretation: J Tu, B Wang; (VI) Manuscript writing: All \\ authors; (VII) Final approval of manuscript: All authors. \\ \#These authors contributed equally to this work. \\ Correspondence to: Jingnan Shen. 58, Zhongshan 2nd Road, Guangzhou, China. Email: shenjn@sysu.edu.cn; Lili Wen. 651, Dongfeng East Road, \\ Guangzhou, China. Email: wenll@sysucc.org.cn.
}

Background: The efficacy of surgical therapy to nonsurgical therapy is still a controversial topic in pelvic Ewing's sarcoma (ES) management. We perform a systemic review and meta-analysis to compare the effect of local control (LC) and survival outcomes between surgical and nonsurgical local therapy on pelvic ES patients with systemic chemotherapy.

Methods: Published retrospective studies searched from PubMed, Embase, Cochrane and Web of Science databases that investigated the effects of surgical and nonsurgical local therapy on the LC and survival outcomes of patients with pelvic ES treated with chemotherapy were included in our study. Our primary outcome was the LC rate and progression-free survival (PFS) rate. The effect of confounders of extend of disease, surgical margin and chemotherapy respond on PFS was analyzed in subgroups.

Results: Ten studies with 782 pelvic ES patients were included in our analysis. Surgical patients showed higher LC and PFS rate comparing to nonsurgical patients [LC: risk ratio (RR) 0.72, 95\% CI: 0.52-1.00, $\mathrm{P}=0.05, \mathrm{I}^{2}=0 \%$; PFS: RR 0.72, 95\% CI: 0.61-0.86, $\mathrm{P}=0.000, \mathrm{I}^{2}=15 \%$ ]. Localized patients showed higher PFS with surgical therapy than nonsurgical patients (RR 0.67, 95\% CI: 0.51-0.88, P=0.003).Patients with adequate resection and good chemotherapy respond improved PFS comparing to nonsurgical patients (adequate resection $v$ s. nonsurgical: RR 0.59, 95\% CI: 0.46-0.76, $\mathrm{P}<0.001, \mathrm{I}^{2}=0 \%$; good respond $v$ s. nonsurgical: RR 0.56, 95\% CI: $0.41-0.77, \mathrm{P}<0.001, \mathrm{I}^{2}=21 \%$ ). But patients with inadequate resection and poor chemotherapeutic respond shows no statistical different PFS comparing to nonsurgical patients (inadequate resection vs. nonsurgical: RR 1.11, 95\% CI: 0.87-1.41, $\mathrm{P}=0.41, \mathrm{I}^{2}=0 \%$; poor respond vs. nonsurgical: $\mathrm{RR} 1.17$, 95\% CI: $0.90-1.52, \mathrm{P}=0.25, \mathrm{I}^{2}=0 \%$ ).

Conclusions: Surgical therapy is primarily recommended in localized, resectable, good chemotherapeutic respond pelvic ES. Inadequate resection and poor chemotherapeutic respond are negative prognostic factors in surgical patients and their surviving are not improved comparing with nonsurgical patients.

Systematic review registration: PROSPERO CRD42020149224.

Keywords: Pelvic Ewing sarcoma (pelvic ES); surgery; radiotherapy; survival

Submitted Feb 27, 2020. Accepted for publication Aug 14, 2020.

doi: $10.21037 /$ tcr-20-1222

View this article at: http://dx.doi.org/10.21037/tcr-20-1222 


\section{Introduction}

Ewing's sarcoma (ES) is the second most common malignant bone tumor in children and adolescents (1). And pelvic is considered one of the most favorite bony location of ES and shows inferior prognosis comparing to ES in extremity (2).

The general therapeutic approach for pelvic ES is a multimodal protocol that include definitive local therapy, including local surgical and nonsurgical therapy, and systemic therapy with induction chemotherapy and postsurgical adjuvant chemotherapy $(3,4)$. Surgical therapy indicates surgical resection of tumor with or without combination of radiotherapy and nonsurgical therapy refers to definitive radiotherapy without surgical resection. For the past decades, both local therapies were the most widely used local treatment in pelvic ES (5). It has improved the prognostic outcome in pelvic ES which is approaching the prognosis in nonpelvic ES patients $(2,4)$. But the decision between surgical and nonsurgical therapy is still remained a challenge. The efficacy of both approaches is still a controversial topic in pelvic ES management. Different centers have reported conflicting results that some reported surgical patients benefited in higher local control (LC) rate comparing nonsurgical patients when other found no difference between them. It is still prone to bias since randomized controlled trials (RCTs) studies are considered infeasible and lack of strong evidence (6).

We present a systematic review of the existing evidence from the published studies to provide a comparation of the effects of surgical therapy with the nonsurgical therapy as local treatment strategies on improving the LC and survival outcomes of pelvic ES patients treated with standard systemic therapy. A meta-analysis was performed to integrate the existing studies and estimate the difference of progression-free survival (PFS) and LC rates between the surgical and nonsurgical therapy pelvic ES patients. We present the following article in accordance with the PRISMA reporting checklist (7) (available at http://dx.doi. org/10.21037/tcr-20-1222).

\section{Methods}

The protocol has been registered on the International Prospective Register of Systematic Reviews (PROSPERO) website with the register ID PROSPERO CRD 42020149224.

\section{Search protocol}

The PubMed, Embase, Cochrane and Web of Science databases were searched from January 1990 to November 1, 2019, and the PROSPERO database was searched up to August 2019 to identify the existing relevant studies. The article language was restricted to English, and search terms "Pelvic" and "Ewing Sarcoma" as well as their alternatives were used to search for both reviews and original papers.

\section{Study selection}

Studies are enrolled in the review if they met the following eligibility criteria: (I) study investigated pelvic ES patients accepted systematic treatment with preoperative and postoperative chemotherapy included vincristine, doxorubicin, cyclophosphamide, ifosfamide and etoposide; (II) patient accepted local treatment with surgical therapy or nonsurgical therapy with definitive radiotherapy; (III) ES is confirmed with histological positive biopsy. The exclusion criteria were as follows: (I) studies published in the form of an animal study or case report; (II) studies included patients with multiple primary ES tumors or primary ES in other sites other than the pelvis; (III) small sample size less than 30 patients; (IV) single-arm treatment studies; (V) repeat studies that reported in the same patients; (VI) therapeutic strategy is unclearly stated.

Initially, two reviewers screened the titles and abstracts from the search results to remove the duplicates and exclude studies that did not align with the review purpose. Then, two reviewers further assessed the full-text publications and confirmed the final study selections.

\section{Data extraction and synthesis}

To define treatment efficacy, we extracted the patient characteristics, interventions and following outcomes from the studies: PFS and LC rates; the data were separately recorded for the different treatment. The patients characteristics include age, gender, tumor size, location in pelvic, extend of disease, LC approaches, radiotherapeutic doses, surgical margin and chemotherapeutic respond. One reviewer extracted data from the included studies with a standard data extraction table. A second reviewer verified and checked the data of the studies. 


\section{Assessment of study quality and risk of bias}

Two reviewers independently examined the study quality and potential risk of bias in estimating the comparative effectiveness of interventions of the included nonrandomized control studies. The "Grading of Recommendations, Assessment, Development, and Evaluation (GRADE)" (8) method was used to assess the study quality, and the "Risk of Bias In Nonrandomized Studies-of Interventions (ROBIN-I)" (9) tool was used to evaluate the risk of bias.

\section{Statistical analysis}

We generated meta-analysis for the included studies to compare their LC and PFS rate among different local treatments. For studies with available survival and LC data, the LC and PFS were directly extracted from the paper. For studies that provide survival curve, Engauge Digitizer (version v12) was used to fit the curve and gather the corresponding data represented in the survival curve (10).

The patients features, outcomes were dichotomous variables and the treatment efficacy was compared with the risk ratio (RR) across trials as pooled estimate using Mantel-Haenszel (M-H) method (11). The interstudy statistical heterogeneity were assessed with the $\mathrm{I}^{2}$ test and the published bias were visualized by funnel plots among these studies. Higher $\mathrm{I}^{2}$ values meant higher percentage of unexplained statistical heterogeneity, which $\mathrm{I}^{2}<25 \%$ indicated low risk in heterogeneity, $25 \% \leq \mathrm{I}^{2}<50 \%$ indicated moderate risk in heterogeneity and $\mathrm{I}^{2} \geq 50 \%$ or $\mathrm{I}^{2}$ test reject the null hypothesis $(\mathrm{P}<0.05)$ indicated high risk in heterogeneity (12). In our study, the selection of appropriate estimated model between fixed-effect and random-effect model is based on different risk level in heterogeneity. Low risk in heterogeneity indicated little statistical uncertainty in the combined effect across the studies that we considered the included studies share a common effect size and fit in a fixed-effect model (13). Moderate to high risk in heterogeneity and reject the $\mathrm{I}^{2}$ hypothesis indicated existing statistical uncertainty in the combined effect across the studies that we considered the effect size of included studies is in distribution and we used a random-effect model to estimate the mean of the effect size (13). The metaanalysis was generated using RevMan software (version 5.3; Cochrane Collaboration) and the rest statistical analysis was achieved with SPSS Statistics software (version 22.0; IBM Corporation).

\section{Results}

\section{Eligible studies and quality assessment}

We identified 878 studies and included 10 retrospective cohort or comparative studies in the review $(5,14-24)$. Figure 1 summarizes the flow diagram of the study retrieval and selection process.

The risk of bias was evaluated and are shown in Table 1 . The ROBINS-I assessment suggested that included studies had moderate to serious risk of bias and the GRADEpro indicated the certainty of evidence was low. The risk of bias and low certainty of evidence was limited to these select report in important confounding domains and patient outcome, suspicious selection in participants, small study populations and missing data.

\section{Patients characteristic}

These studies included a total of 921 pelvic ES patients and $84.91 \%$ (782/921) patients with reported outcomes and administration of local management and standard systemic therapy were enrolled in the meta-analysis. The patient characteristic across the enrolled studies were listed in Table 2. They were follow-up a duration ranging from 25.9 to 99.6 months (median 66 months). The pelvic ES patients consisted of $56.78 \%$ (444/782) patients accepted surgical therapy and $43.22 \%$ (338/782) patients accepted nonsurgical therapy. Among the surgical resection patients, $63.51 \%(282 / 444)$ received a combination of adjuvant radiotherapy, which was applied additional to surgery based on surgeon decision. The nonoperative patients received definitive radiotherapy with radiation doses ranged from 50-66 Gy. The adjuvant radiation doses were in range from 40-55 Gy.

\section{Primary outcome: PFS and LC}

The forest plot of LC and PFS between surgical patients and nonsurgical patients was showed in Figure 2. We detected mild risk of statistical heterogeneity and applied a fixed effected model (PFS: $\mathrm{I}^{2}=15 \%$; LC: $\mathrm{I}^{2}=0 \%$; Funnel plot in Figure 3). Among 10 studies with reported PFS, 3 studies reported higher PFS rate in surgical patients than nonsurgical patients and the rest reported no difference. The pool estimates showed surgical patients improved PFS rate comparing to nonsurgical patients (RR $0.72,95 \% \mathrm{CI}$ : $0.61-0.86, \mathrm{P}<0.001)$.

Among the included studies, 9 studies were compared 


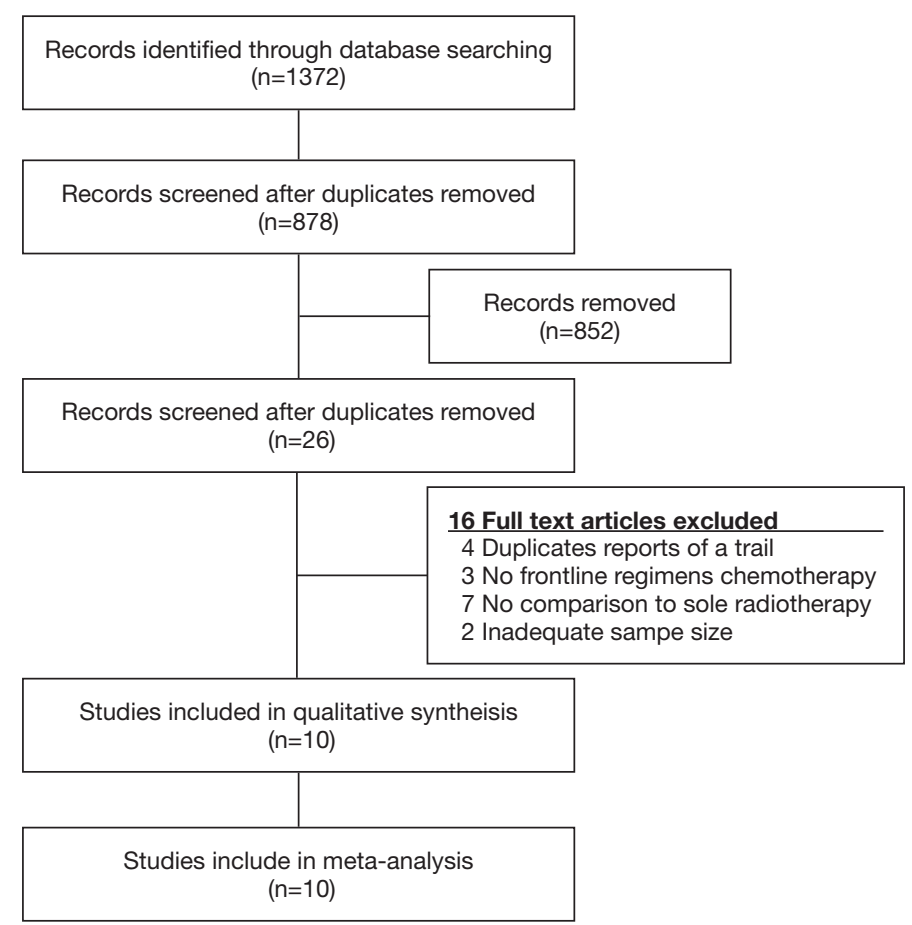

Figure 1 Flowchart of studies enrolled and meta-analysis.

Table 1 Assessment of risk of bias ${ }^{\dagger}$

\begin{tabular}{|c|c|c|c|c|c|c|c|c|}
\hline Author & \multicolumn{3}{|c|}{ Pre-intervention } & \multicolumn{4}{|c|}{ Post-intervention } & $\begin{array}{c}\text { Overall } \\
\text { ROB }\end{array}$ \\
\hline Ahmed & Serious & Low & Moderate & Moderate & Low & Low & Moderate & Serious \\
\hline Hesla & Serious & Low & Moderate & Moderate & Moderate & Low & Serious & Serious \\
\hline Dannel & Serious & Low & Moderate & Moderate & Low & Low & Serious & Serious \\
\hline Donati & Moderate & Low & Moderate & Moderate & Low & Low & Moderate & Moderate \\
\hline Yock & Serious & Moderate & Moderate & Moderate & Low & Low & Serious & Serious \\
\hline
\end{tabular}

${ }^{\dagger}$, the risk of bias is evaluated with the risk of bias in non-randomized studies of interventions (ROBINS-I) assessment tool. The confounding domains listed extend of disease, surgical margin and histologic respond to chemotherapy; the additional confounding domains listed gender, age and tumor size; the primary outcome includes local failure and disease relapse. 
Table 2 Patients characteristics

\begin{tabular}{|c|c|c|c|c|c|c|c|c|}
\hline Author & $\mathrm{n}$ & $\begin{array}{l}\text { Year of } \\
\text { study }\end{array}$ & $\begin{array}{c}\text { Gender } \\
\text { (male/female) }\end{array}$ & Age (years) & Tumor size & $\begin{array}{l}\text { Location in } \\
\text { pelvis }\end{array}$ & $\begin{array}{l}\text { Inpatient } \\
\text { metastasis }\end{array}$ & Follow-up (months) \\
\hline Ahmed & 48 & 1990-2012 & $33 / 15$ & $\begin{array}{c}\text { Median } 20.0 \\
\text { (range 6.6-64.9) }\end{array}$ & $\begin{array}{l}<8 \mathrm{~cm}: 8 \\
\geq 8 \mathrm{~cm} 19\end{array}$ & $\begin{array}{c}\text { Sacrum: } 15 ; \\
\text { nonsacrum: } 33\end{array}$ & 25 & $\begin{array}{c}\text { Median } 99.6 \\
\text { (range: } 1.2-256.8 \text { ) }\end{array}$ \\
\hline Andreou & 180 & 1998-2009 & $102 / 78$ & $\begin{array}{c}\text { Median } 17 \\
\text { (range 0.02-60) }\end{array}$ & $\begin{array}{l}<200 \text { mL: } 79 \\
\geq 200 \text { mL } 95\end{array}$ & $\begin{array}{c}\text { Sacrum: } 40 ; \\
\text { nonsacrum: } 140\end{array}$ & 0 & $\begin{array}{c}\text { Median } 54 \\
\text { (range: } 5-191 \text { ) }\end{array}$ \\
\hline Dannel & 35 & 1970-2005 & $21 / 14$ & $<15: 11 ; \geq 15: 24$ & $\begin{array}{l}<8 \mathrm{~cm}: 9 \\
\geq 8 \mathrm{~cm} 26\end{array}$ & No mention & 0 & $\begin{array}{c}\text { Median } 48 \\
\text { (range: } 3.6-364.8 \text { ) }\end{array}$ \\
\hline Donati & 73 & 1975-1999 & $32 / 24$ & $\begin{array}{l}\text { Median } 18.4 \\
\text { (range 6-46) }\end{array}$ & $\begin{array}{l}<150 \mathrm{~mL}: 27 \\
\geq 150 \mathrm{~mL}: 26\end{array}$ & $\begin{array}{c}\text { Sacrum: } 11 ; \\
\text { nonsacrum: } 45\end{array}$ & 0 & $\begin{array}{l}\text { Median } 87.2 \\
\text { (range: } 7-272 \text { ) }\end{array}$ \\
\hline Hoffmann & 241 & $1981-1994$ & $140 / 101$ & $\begin{array}{c}\text { Mean } 16 \\
\text { (range 1-41) }\end{array}$ & $\begin{array}{l}<100 \mathrm{~mL}: 22 \\
\geq 100 \mathrm{~mL} 118\end{array}$ & $\begin{array}{c}\text { Sacrum: } 28 ; \\
\text { nonsacrum: } 136\end{array}$ & 77 & $\begin{array}{l}\text { Median } 25.9 \\
\text { (range: } 1-163 \text { ) }\end{array}$ \\
\hline Vincent & 40 & 1990-2014 & No mention & $\begin{array}{c}\text { Median } 18.7 \\
\text { (range 6.0-57.0) }\end{array}$ & $\begin{array}{c}\text { Mean } 9.5 \mathrm{~cm} \text { in S; } \\
11.1 \mathrm{~cm} \text { in Rt }\end{array}$ & $\begin{array}{c}\text { Sacrum: 7; } \\
\text { nonsacrum: } 33\end{array}$ & 20 & $\begin{array}{c}\text { Median } 84.5 \text { in S; } \\
19.5 \text { in Rt; } 77.0 \text { in Comb }\end{array}$ \\
\hline Yock & 75 & 1988-1992 & $39 / 36$ & $\begin{array}{c}\leq 9: 14 ; 10-17: 48 \\
\geq 18: 13\end{array}$ & $\begin{array}{l}<8 \mathrm{~cm}: 37 \\
\geq 8 \mathrm{~cm}: 38\end{array}$ & No mention & 0 & $\begin{array}{c}\text { Median } 52.8 \\
\text { (range: } 7.2-136.8 \text { ) }\end{array}$ \\
\hline
\end{tabular}

Rt stands for definitive radiotherapy; $\mathrm{S}$ stands for surgical resection alone; Comb stands for combination of surgery with adjuvant radiotherapy.

with LC and no studies reported a difference performance in LC between surgical and nonsurgical patients. The result favored surgical therapy that surgical patients showed higher LC rate than nonsurgical therapy (RR 0.72, 95\% CI: $0.52-1.00, \mathrm{P}=0.05)$.

\section{Effect of surgical therapy on localized pelvic ES patients}

7 studies reported the disease progression outcomes of nonmetastatic cases (Figure 4). Among these reports, we detected moderate statistical heterogeneity and applied a random effected model (PFS: $\mathrm{I}^{2}=34 \%$; LC: $\mathrm{I}^{2}=0 \%$ ). The localized patients with surgical resection showed higher PFS comparing to nonsurgical patients (PFS: RR 0.67, 95\% CI: 0.51-0.88, P=0.003; LC: RR 0.76, 95\% CI: 0.55-1.06, $\mathrm{P}=0.11)$.

Four studies included 164 metastatic patients at presentation. The PFS rate in primarily metastatic patients were significantly poorer than the localized patients (RR
1.85, 95\% CI: $\left.1.57-2.19, \mathrm{P}<0.001, \mathrm{I}^{2}=0 \%\right)$. But no included studies reported the outcomes between different LC approaches on metastatic patients and the subgroup analysis remained infeasible.

\section{Effect of surgical therapy on inadequate resection margin patients}

Five studies reported disease relapsed on the subgroup between adequate and inadequate resection patients (Figure 5). The $26.4 \%(77 / 292)$ of these patients are affected with inadequate resection. PFS rate is negative associated with inadequate resection comparing with the adequate patients (RR 1.71, 95\% CI: $1.32-2.21, \mathrm{P}<0.001, \mathrm{I}^{2}=0 \%$ ). The PFS in adequate resected patients was improved comparing with nonsurgical patients (RR 0.59, 95\% CI: 0.46-0.76, $\mathrm{P}<0.001$, $\left.\mathrm{I}^{2}=0 \%\right)$. And it showed no statistical difference in PFS between the inadequate resected patients and nonsurgical patients (RR 1.11, 95\% CI: 0.87-1.41, $\mathrm{P}=0.41, \mathrm{I}^{2}=0 \%$ ). 

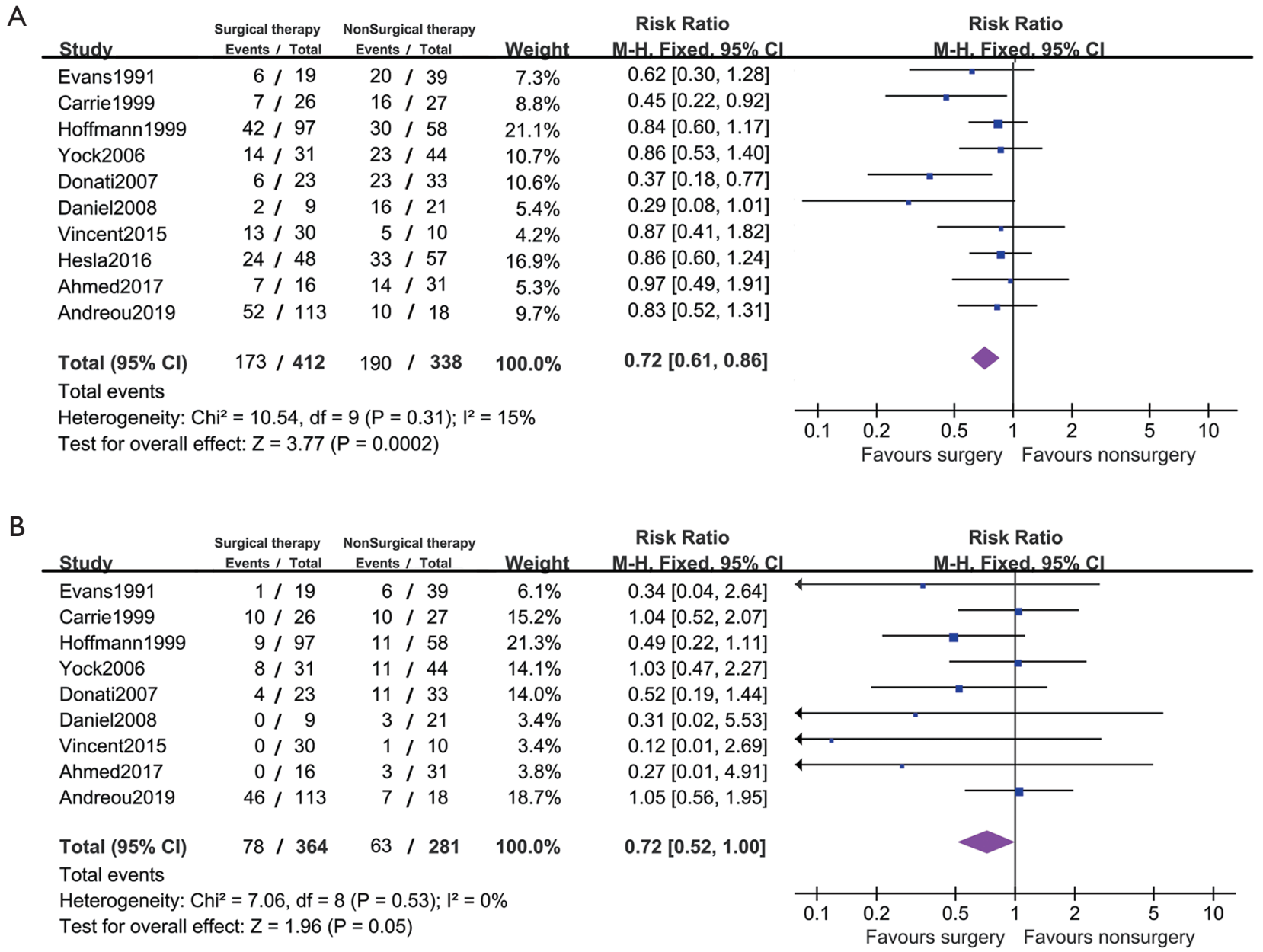

Figure 2 Forest plots showing RR of LC and PFS between surgical therapy and nonsurgical therapy groups. (A) Progression free survival; (B) local control. RRs were calculated using the M-H method to combine summary statistics, and data were pooled using a fixed-effects model. M-H method, Mantel-Haenszel method; RR, risk ratio; CI, confidence intervals; LC, local control; PFS, progression free survival.
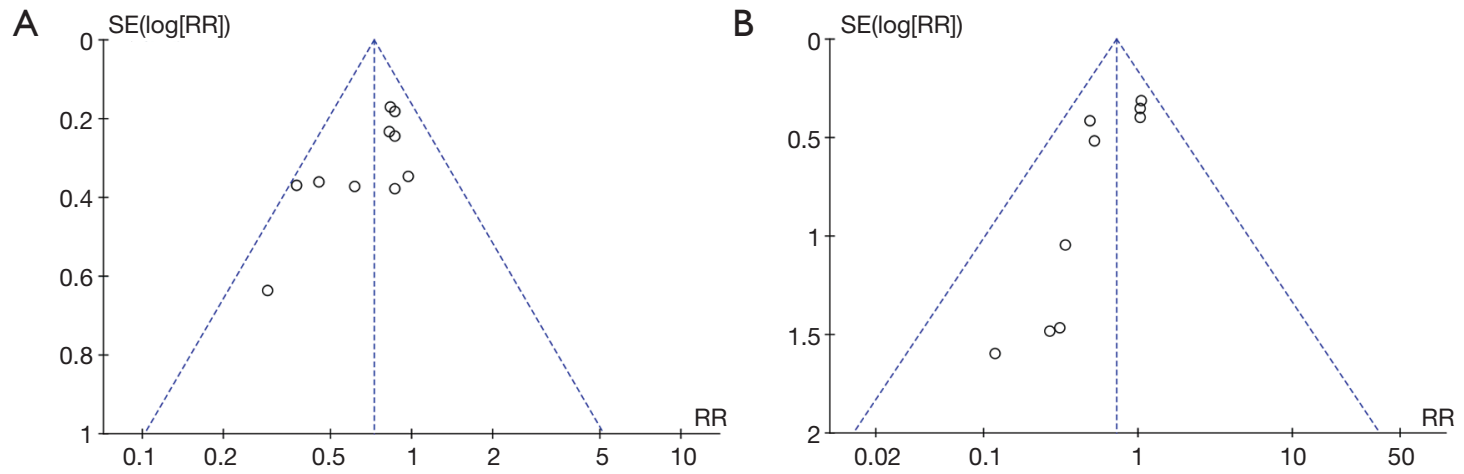

Figure 3 Funnel plot of $\log$ RR of PFS and LC in pool estimate showing the publication bias among included studies. (A) Progression free survival; (B) local control. SE, standard error; RR, risk ratio; LC, local control; PFS, progression free survival. 
A

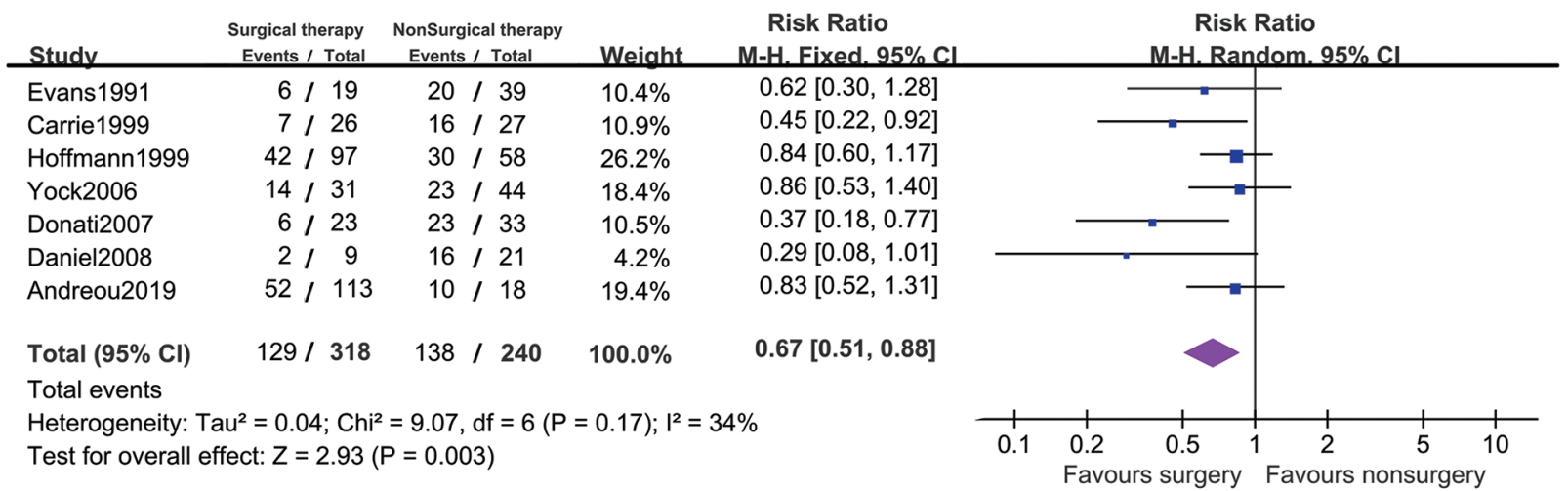

B

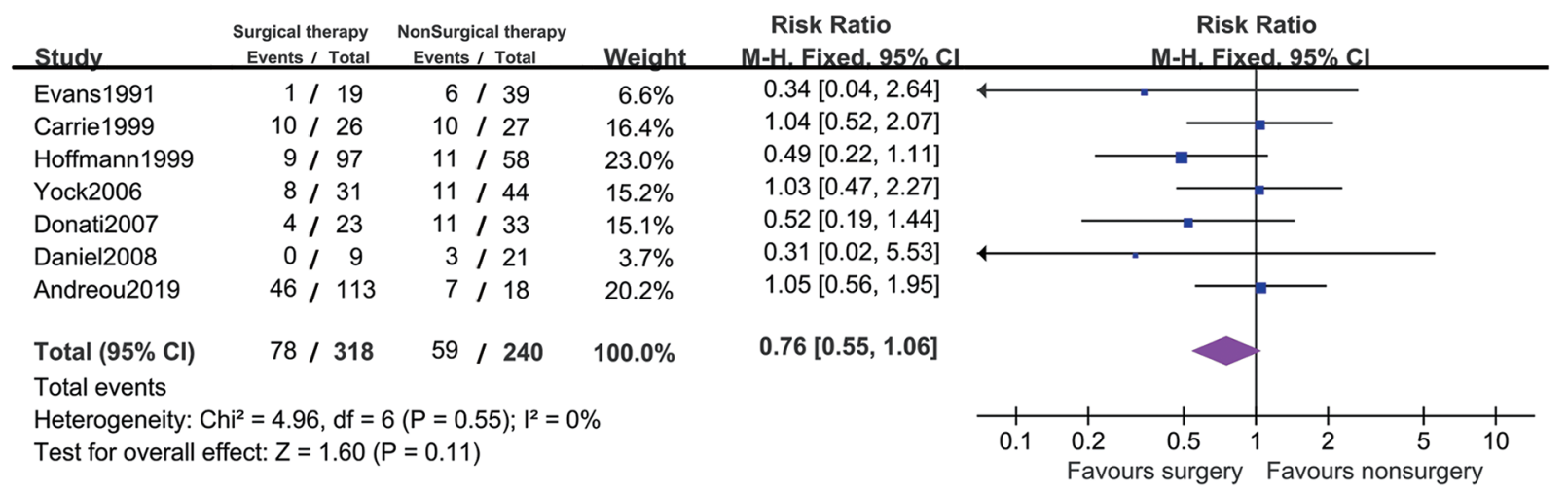

C

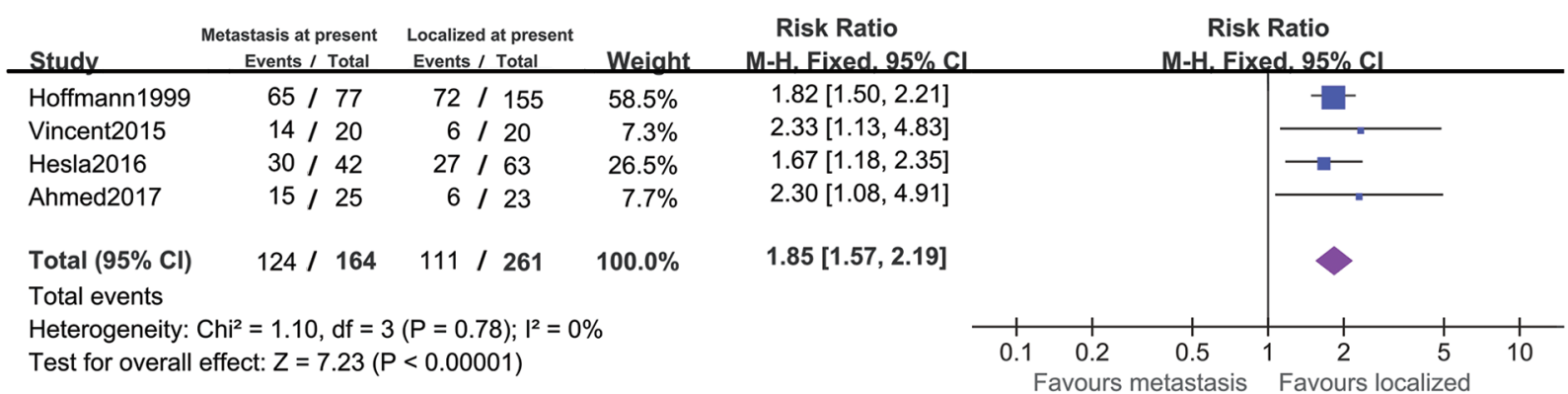

Figure 4 Subgroup forest plots showing RR of LC and PFS in metastatic and localized patients between surgical and nonsurgical therapy. (A) PFS in localized patients between surgical and nonsurgical therapy; (B) LC in localized patients between surgical and nonsurgical therapy; (C) PFS in pool estimated between localized and metastatic patients. RR were calculated using the M-H method to combine summary statistics, and (A) was estimated using a random-effects model, (B,C) using fixed-effects model. M-H method, Mantel-Haenszel method; RR, risk ratio; CI, confidence intervals; LC, local control; PFS, progression free survival.

\section{Effect of surgical therapy on poor chemotherapeutic respond patients}

Four studies reported disease relapsed on the subgroup between good and poor chemotherapeutic respond patients (Figure 6). These patients are $28.70 \%(64 / 223)$ of $\leq 90 \%$ necrosis which is considered poor respond to chemotherapy.
The poor respond patients had lower PFS comparing with those with good respond (RR 1.95, 95\% CI: 1.47-2.59, $\left.\mathrm{P}<0.001, \mathrm{I}^{2}=0 \%\right)$. In a fixed effected model, it suggested patient with poor respond showed no statistical difference in PFS between administration with surgical and nonsurgical therapy (RR 1.17, 95\% CI: 0.90-1.52, $\mathrm{P}=0.25, \mathrm{I}^{2}=0 \%$ ). 
A

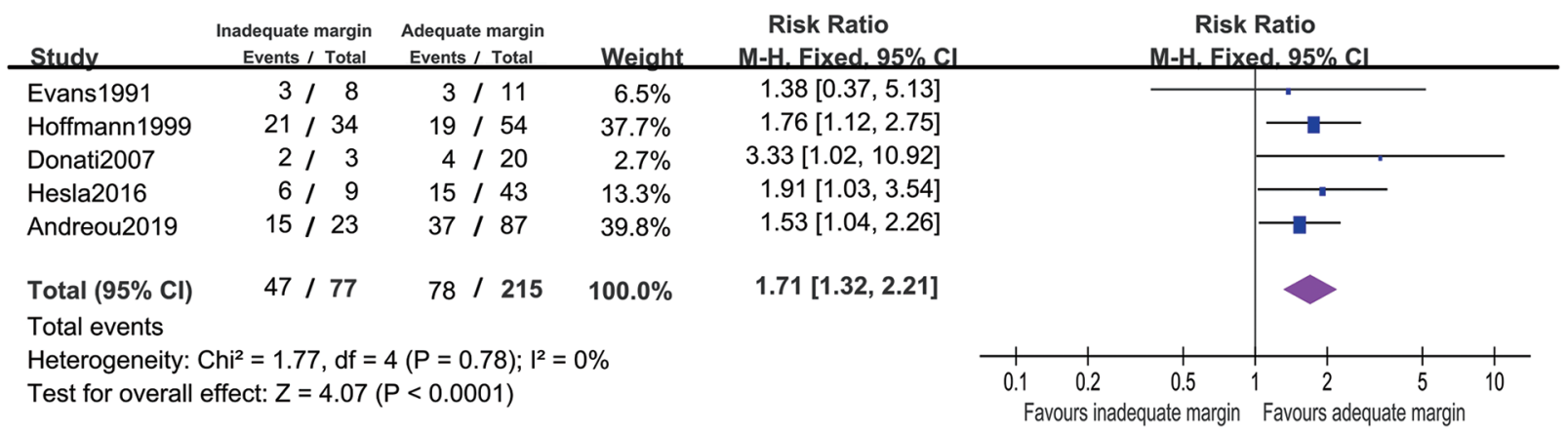

B

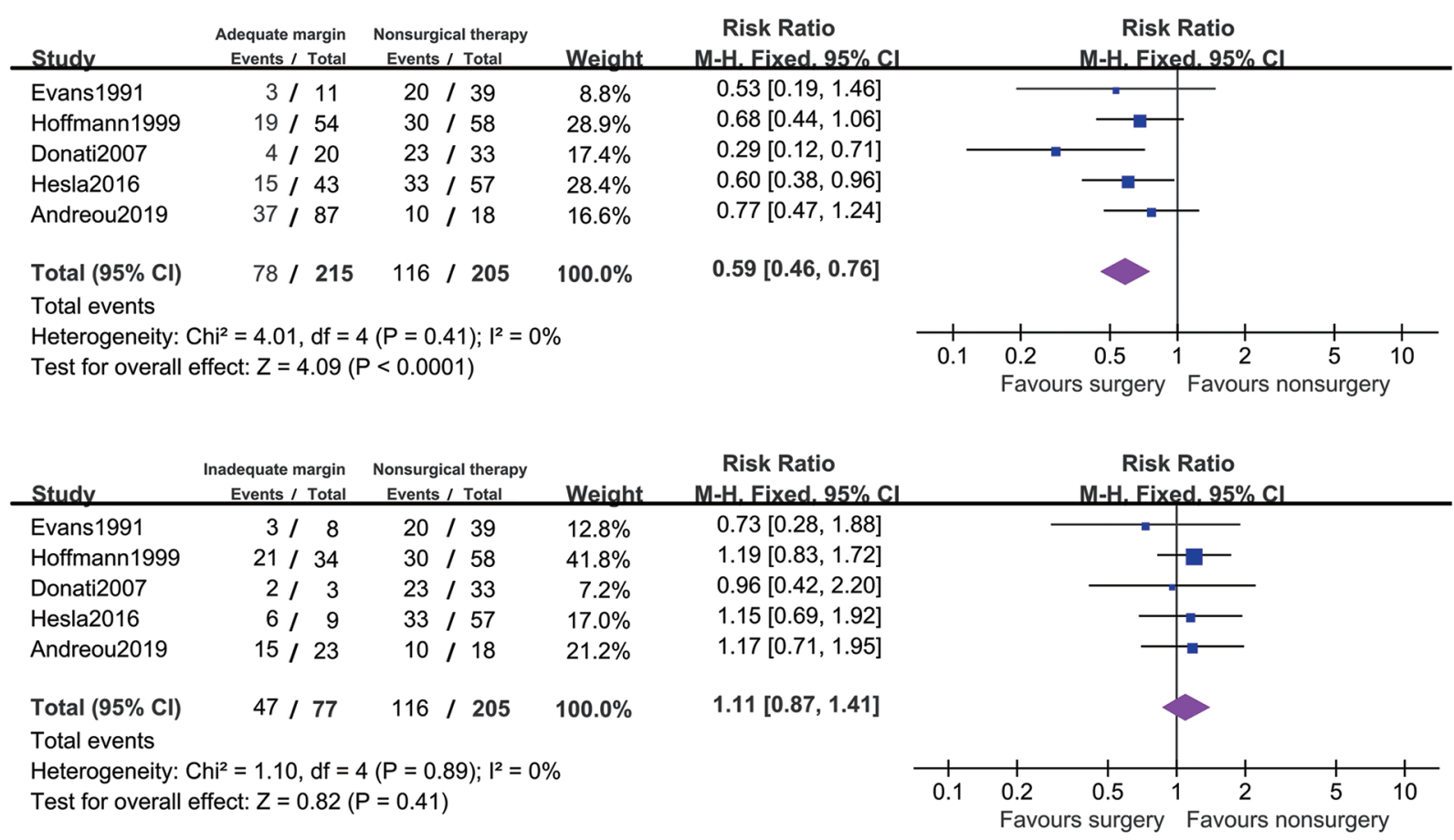

Figure 5 Subgroup forest plots showing RR of PFS in adequate and inadequate resection patients. (A) PFS between adequate and inadequate resection patients; (B) PFS between adequate resection patients and nonsurgical therapy patients; (C) PFS between inadequate resection patients and nonsurgical therapy patients. RR were calculated using the $\mathrm{M}-\mathrm{H}$ method to combine summary statistics, and the data was pool estimated using fixed-effects model. M-H method, Mantel-Haenszel method; RR, risk ratio; CI, confidence intervals; PFS, progression free survival.

In good respond model, surgical patients appeared to had better PFS with surgery comparing to nonsurgical therapy (RR 0.56, 95\% CI: $0.41-0.77, \mathrm{P}<0.001, \mathrm{I}^{2}=21 \%$ ).

\section{Discussion}

In this meta-analysis of the 10 retrospective studies, a total of 782 eligible pelvic ES patients are enrolled, including 444 with surgical therapy and 338 with nonsurgical therapy. Among existing reports, we find that patients with surgical therapy shows better performance in PFS and LC comparing to nonsurgical patients (PFS: RR 0.72, 95\% CI: 0.61-0.86, $\mathrm{P}<0.001$; LC: RR 0.72, 95\% CI: 0.52-1.00, $\mathrm{P}=0.05)$. Furthermore, we apply subgroup analysis to demonstrate effect of surgical therapy on patient outcome among different extend of disease, surgery margin and chemotherapeutic respond.

Surgical patients are reported advantage in surviving 


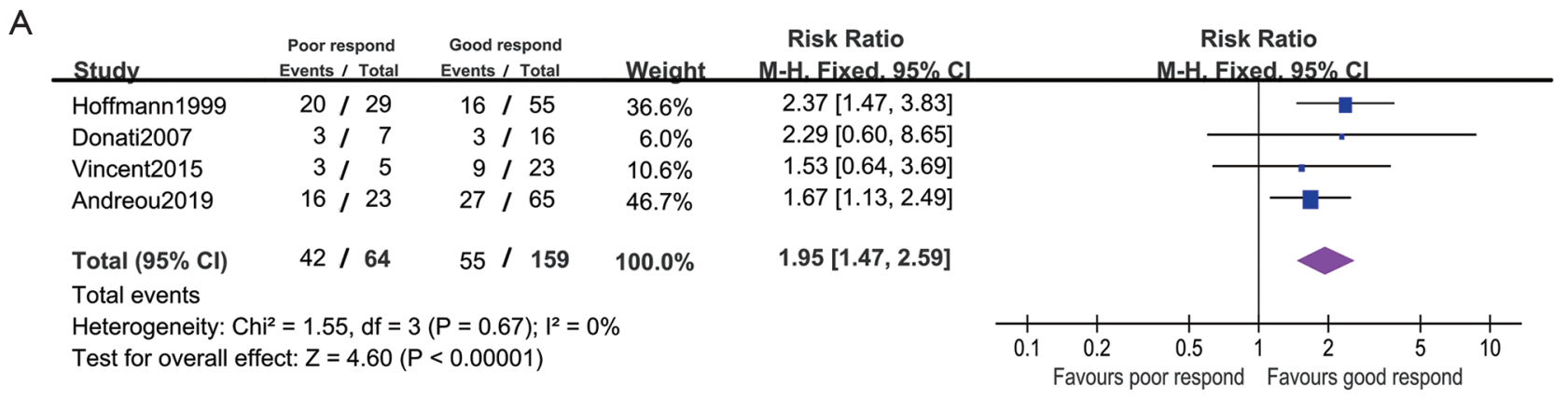

B

\begin{tabular}{lrrrr} 
Study & $\begin{array}{c}\text { Good respond } \\
\text { Events / Total }\end{array}$ & $\begin{array}{c}\text { Nonsurgical therapy } \\
\text { Events / Total }\end{array}$ & Wei \\
\hline Andreou2019 & $27 / 65$ & $10 / 18$ & $23.4 \%$ \\
Donati2007 & $3 / 16$ & $23 / 33$ & $22.5 \%$ \\
Hoffmann1999 & $16 / 55$ & $30 / 58$ & $43.7 \%$ \\
Vincent2015 & $9 / 23$ & $5 / 10$ & $10.4 \%$ \\
Total (95\% Cl) & $55 / 159$ & $68 / 119$ & $100.0 \%$ \\
Total events & \\
Heterogeneity: Chi ${ }^{2}=3.79, \mathrm{df}=3(\mathrm{P}=0.29) ; I^{2}=21 \%$ \\
Test for overall effect: $\mathrm{Z}=3.58(\mathrm{P}=0.0003)$
\end{tabular}

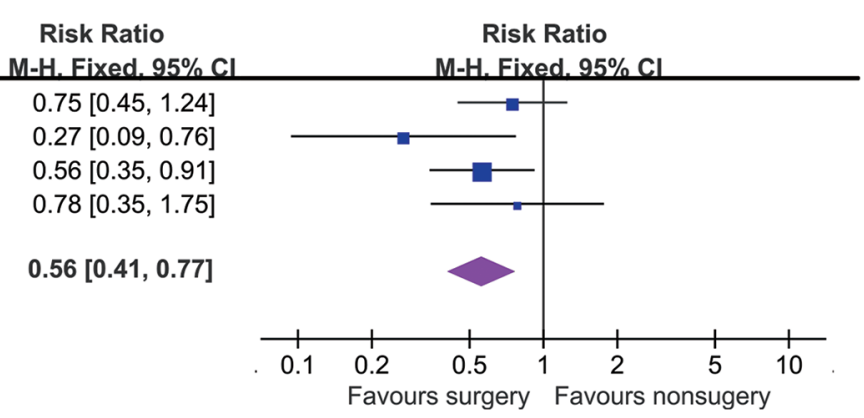

C

\begin{tabular}{|c|c|c|c|}
\hline Study & $\begin{array}{l}\text { Poor respond } \\
\text { Events / Total }\end{array}$ & $\begin{array}{c}\text { Nonsurgical therapy } \\
\text { Events / Total }\end{array}$ & Weight \\
\hline Hoffmann1999 & $20 / 29$ & 30 / 58 & $46.9 \%$ \\
\hline Donati2007 & $3 / 7$ & $23 / 33$ & $18.9 \%$ \\
\hline Vincent2015 & $3 / 5$ & $5 / 10$ & $7.8 \%$ \\
\hline Andreou2019 & $16 / 23$ & $10 / 18$ & $26.3 \%$ \\
\hline Total $(95 \% \mathrm{Cl})$ & $42 / 64$ & $68 / 119$ & $100.0 \%$ \\
\hline $\begin{array}{l}\text { Total events } \\
\text { Heterogeneity: } \\
\text { Test for overall }\end{array}$ & $\begin{array}{l}=2.66, \mathrm{df}=3 \\
\mathrm{ct}: Z=1.14\end{array}$ & $\begin{array}{l}3(P=0.45) ;\left.\right|^{2}= \\
P=0.25)\end{array}$ & \\
\hline
\end{tabular}

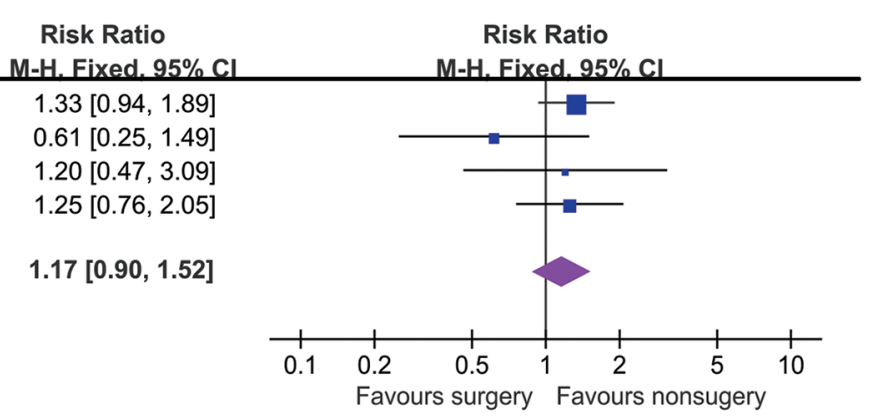

Figure 6 Subgroup forest plots showing RR of PFS in good and poor chemotherapeutic respond patients. (A) PFS between good and poor chemotherapeutic respond patients; (B) PFS between good chemotherapeutic respond patients and nonsurgical therapy; (C) PFS between poor chemotherapeutic respond patients and nonsurgical therapy. RR were calculated using the M-H method to combine summary statistics, and the data was pool estimated using fixed-effects model. M-H method, Mantel-Haenszel method; RR, risk ratio; CI, confidence intervals; PFS, progression free survival.

comparing to nonsurgical LC approaches based on population research $(25,26)$. Our study reveals that patients with surgical therapy have higher PFS and LC than nonsurgical patients (PFS: RR 0.72, 95\% CI: 0.61-0.86, $\mathrm{P}<0.001$; LC: RR 0.72, 95\% CI: 0.52-1.00, $\mathrm{P}=0.05)$. It is consistent with previous literature review showing patients with surgical therapy in pelvic ES management generally obtained better outcome than those with nonsurgical local therapy (5). But in mixed site ES, it is accepted that surgical patients are often considered to show statistically comparable OS an PFS rate to those without surgical therapy (27). We assume it as a result of the pelvic ES is differentiated from the extremity ES for its larger volume and relatively radiation-resistant which indicates poor effect of the nonsurgical therapy (28). In localized patients, we notice surgical patients consistently shows advantages in PFS comparing those without surgery (RR 0.67, 95\% CI: $0.51-0.88, \mathrm{P}=0.003)$. But no included studies report the subgroup outcomes among different LC approaches in patients and the metastatic subgroup analysis remained 
infeasible. It suggests the localized patients is recommended to have surgical resection and further investigation is needed to illustrate the local approaches effect on primary metastatic patients.

The administration of surgical therapy is challenging with inadequate surgical margin in pelvic ES (28). From the included studies, we notice that up to $26.4 \%$ surgical patients are reported inadequate margins. The results show patients PFS is negative associated with inadequate margin to the adequate resected patients (RR 1.71, 95\% CI: $1.32-2.21, \mathrm{P}<0.001)$. And the adequate resected patients show higher PFS to the nonsurgical patients (RR 0.59, 95\% CI: $0.46-0.76, \mathrm{P}<0.001)$. It is consistent with the previous report that adequate surgical margin helps patients obtain significantly reduced local recurrences and improved the PFS $(29,30)$. The patients with inadequate margin show no statistical difference in PFS to those nonsurgical patients (RR 1.11, 95\% CI: $0.87-1.41, \mathrm{P}=0.41$ ). The inadequate resection is related to intrasurgical tumor dissemination and appear higher risk in developing local and combined relapses (29). It suggests that surgical resection is primarily recommended in resectable pelvic ES patients and surgeon should consider the feasibility of adequate resection of the primary tumor before the administration of surgery resection.

Histologic respond to chemotherapy is also one of important prognostic factors in ES treatment (27). Patients with poor histologic chemotherapeutic respond is related to higher risk in disease relapsed, even for adequate resection patients (31). We find $28.70 \%$ surgical patients affected with poor histologic respond and they had higher risks in disease progression comparing to the good respond patients (RR 1.95, 95\% CI: 1.47-2.59, $\mathrm{P}<0.001)$. The poor respond patients have no significant difference in PFS to nonsurgical patients (RR 1.17, 95\% CI: 0.90-1.52, $\mathrm{P}=0.25$ ), while the good respond patients have advantage in PFS comparing with nonsurgical patients (RR 0.56, 95\% CI: 0.41-0.77, $\mathrm{P}<0.001)$. Previous study reports that the poor respond patients are more likely to develop postsurgical progression in 1 year which led to particular poor outcomes (31). Thus, it is important to assess the chemotherapeutic respond after surgical procedure to guide patient's prognosis and the postsurgical treatment. However, it remains a challenge to evaluate the chemotherapy respond before the surgery (32). The radiographic respond is one of noninvasive assessment methods of the chemotherapeutic respond. And the radiographic assessment appears to show higher correlation to ES therapeutic respond and prognosis than
RECIST assessment (33). It suggested surgeon should evaluate patients chemotherapeutic respond before the administration of surgery resection and administration of surgery is recommended in the good respond patients while it should be considered carefully in poor respond patients.

Our review is limited by several weaknesses. First, the pelvic ES studies are sporadically reported in metastatic subgroups outcome between surgery and nonsurgical therapy among the existing trails. It induces difficulties in subgroup analysis of the surgical or nonsurgical therapy indications in metastatic pelvic ES Second, the followup period is long in pelvic ES studies. Thus, baseline confounders on the influence of different treatments on patient survival inevitably exist like local technique like limb sparing surgery and modern radiotherapeutic methods were not used in old era $(3,4,34-37)$. Third, our review is limited by no eligible high-quality evidence like RCT researches. It recommends the observation studies reports concrete clinical manifestation and reduce their bias on influence patient's prognosis.

\section{Conclusions}

Administration of Surgical therapy is primarily recommended in localized, resectable and good chemotherapeutic respond to nonsurgical therapy in pelvic ES. Inadequate resection and poor chemotherapeutic respond are negative prognostic factors in surgical patients and PFS in these patients with administration of surgery are not statistically different to nonsurgical patients.

\section{Acknowledgments}

Funding: This work was supported by the National Natural Science Foundation of China $(81772861,81202118$, 81572638, 81772864).

\section{Footnote}

Reporting Checklist: The authors have completed the PRISMA reporting checklist. Available at http://dx.doi. org/10.21037/tcr-20-1222

Peer Review File: Available at http://dx.doi.org/10.21037/tcr20-1222

Conflicts of Interest: All authors have completed the ICMJE uniform disclosure form (available at http://dx.doi. 
org/10.21037/tcr-20-1222). The authors have no conflicts of interest to declare.

Ethical Statement: The authors are accountable for all aspects of the work in ensuring that questions related to the accuracy or integrity of any part of the work are appropriately investigated and resolved.

Open Access Statement: This is an Open Access article distributed in accordance with the Creative Commons Attribution-NonCommercial-NoDerivs 4.0 International License (CC BY-NC-ND 4.0), which permits the noncommercial replication and distribution of the article with the strict proviso that no changes or edits are made and the original work is properly cited (including links to both the formal publication through the relevant DOI and the license). See: https://creativecommons.org/licenses/by-nc-nd/4.0/.

\section{References}

1. Burningham $Z$, Hashibe $M$, Spector L, et al. The Epidemiology of Sarcoma. Clin Sarcoma Res 2012;2:14.

2. Paulussen M, Ahrens S, Dunst J, et al. Localized Ewing Tumor of Bone: Final Results of the Cooperative Ewing's Sarcoma Study CESS 86. J Clin Oncol 2001;19:1818-29.

3. Morris CD. Pelvic bone sarcomas: controversies and treatment options. J Natl Compr Canc Netw 2010;8:731-7.

4. Andreou D, Ranft A, Gosheger G, et al. Which Factors Are Associated with Local Control and Survival of Patients with Localized Pelvic Ewing's Sarcoma? A Retrospective Analysis of Data from the Euro-EWING99 Trial. Clin Orthop Relat Res 2020;478:290-302.

5. Indelicato DJ, Keole SR, Shahlaee AH, et al. Impact of local management on long-term outcomes in Ewing tumors of the pelvis and sacral bones: the University of Florida experience. Int J Radiat Oncol Biol Phys 2008;72:41-8.

6. Bacci G, Ferrari S, Mercuri M, et al. Multimodal therapy for the treatment of nonmetastatic Ewing sarcoma of pelvis. J Pediatr Hematol Oncol 2003;25:118-24.

7. Liberati A, Altman DG, Tetzlaff J, et al. The PRISMA statement for reporting systematic reviews and metaanalyses of studies that evaluate health care interventions: explanation and elaboration. PLoS Med 2009;6:e1000100.

8. Balshem H, Helfand $M$, Schunemann HJ, et al. GRADE guidelines: 3. Rating the quality of evidence. J Clin Epidemiol 2011;64:401-6.
9. Sterne JA, Hernan MA, Reeves BC, et al. ROBINS-I: a tool for assessing risk of bias in non-randomised studies of interventions. BMJ 2016;355:14919.

10. Mark M, Tobias W. Markummitchell/engauge-digitizer: New point types. 2019.

11. Kuritz SJ, Landis JR, Koch GG. A General Overview of Mantel-Haenszel Methods: Applications and Recent Developments. Annu Rev Public Health 1988;9:123-60.

12. Huedo-Medina TB, Sanchez-Meca J, Marin-Martinez F, et al. Assessing heterogeneity in meta-analysis: Q statistic or I2 index? Psychol Methods 2006;11:193-206.

13. Borenstein M, Hedges LV, Higgins JP, et al. A basic introduction to fixed-effect and random-effects models for meta-analysis. Res Synth Methods 2010;1:97-111.

14. Ahmed SK, Robinson SI, Arndt CAS, et al. Pelvis Ewing sarcoma: Local control and survival in the modern era. Pediatr Blood Cancer 2017;64.

15. Hesla AC, Tsagozis P, Jebsen N, et al. Improved Prognosis for Patients with Ewing Sarcoma in the Sacrum Compared with the Innominate Bones: The Scandinavian Sarcoma Group Experience. J Bone Joint Surg Am 2016;98:199-210.

16. Ng VY, Jones R, Bompadre V, et al. The effect of surgery with radiation on pelvic Ewing sarcoma survival. J Surg Oncol 2015;112:861-5.

17. Yock TI, Krailo M, Fryer CJ, et al. Local control in pelvic Ewing sarcoma: analysis from INT-0091--a report from the Children's Oncology Group. J Clin Oncol 2006;24:3838-43.

18. Bacci G, Ferrari S, Mercuri M, et al. Multimodal therapy for the treatment of nonmetastatic Ewing sarcoma of pelvis. J Pediatr Hematol/Oncol 2003;25:118-24.

19. Porsch M, Kornhuber B, Hovy L. Functional results after partial pelvic resection in Ewing's sarcoma of the ilium. Arch Orthop Trauma Surg 1999;119:199-204.

20. Hoffmann C, Ahrens S, Dunst J, et al. Pelvic Ewing sarcoma: a retrospective analysis of 241 cases. Cancer 1999;85:869-77.

21. Carrie C, Mascard E, Gomez F, et al. Nonmetastatic pelvic Ewing sarcoma: report of the French society of pediatric oncology. Med Pediatr Oncol 1999;33:444-9.

22. Burgers JM, Oldenburger F, de Kraker J, et al. Ewing's sarcoma of the pelvis: changes over 25 years in treatment and results. Eur J Cancer 1997;33:2360-7.

23. Evans RG, Nesbit ME, Gehan EA, et al. Multimodal therapy for the management of localized Ewing's sarcoma of pelvic and sacral bones: a report from the second intergroup study. J Clin Oncol 1991;9:1173-80. 
24. Donati D, Yin J, Di Bella C, et al. Local and distant control in non-metastatic pelvic Ewing's sarcoma patients. J Surg Oncol 2007;96:19-25.

25. Chen L, Long C, Liu J, et al. Characteristics and prognosis of pelvic Ewing sarcoma: a SEER population-based study. Peer J 2019;7:e7710.

26. Ning MS, Perkins SM, Borinstein SC, et al. Role of radiation in the treatment of non-metastatic osseous Ewing sarcoma. J Med Imaging Radiat Oncol 2016;60:119-28.

27. Paulussen M, Ahrens S, Dunst J, et al. Localized Ewing tumor of bone: final results of the cooperative Ewing's Sarcoma Study CESS 86. J Clin Oncol 2001;19:1818-29.

28. Yang RS, Eckardt JJ, Eilber FR, et al. Surgical indications for Ewing's sarcoma of the pelvis. Cancer 1995;76:1388-97.

29. Ozaki T, Hillmann A, Hoffmann C, et al. Significance of surgical margin on the prognosis of patients with Ewing's sarcoma. A report from the Cooperative Ewing's Sarcoma Study. Cancer 1996;78:892-900.

30. Sluga M, Windhager R, Lang S, et al. The role of surgery and resection margins in the treatment of Ewing's sarcoma. Clin Orthop Relat Res 2001;(392):394-9.

31. Pan HY, Morani A, Wang WL, et al. Prognostic factors and patterns of relapse in ewing sarcoma patients treated with chemotherapy and $\mathrm{r} 0$ resection. Int $\mathrm{J}$ Radiat Oncol

Cite this article as: Xie X, Zeng Z, Yao H, Jin Q, Bian Y, Lv D, Tu J, Wang B, Wen L, Shen J. Comparison of local control and survival outcomes between surgical and non-surgical local therapy on pelvic Ewing's sarcoma patients: a meta-analysis. Transl Cancer Res 2020;9(10):6166-6177. doi: 10.21037/tcr20-1222
Biol Phys 2015;92:349-57.

32. Haveman LM, Ranft A, Vd Berg H, et al. The relation of radiological tumor volume response to histological response and outcome in patients with localized Ewing Sarcoma. Cancer Med 2019;8:1086-94.

33. Aghighi M, Boe J, Rosenberg J, et al. Three-dimensional Radiologic Assessment of Chemotherapy Response in Ewing Sarcoma Can Be Used to Predict Clinical Outcome. Radiology 2016;280:905-15.

34. Fujiwara T, Lex JR, Stevenson JD, et al. Surgical treatment for pelvic Ewing sarcoma: What is a safe and functional acetabular reconstruction when combined with modern multidisciplinary treatments? J Surg Oncol 2019;120:985-93.

35. Evrard R, Schubert T, Paul L, et al. Resection margins obtained with patient-specific instruments for resecting primary pelvic bone sarcomas: A case-control study. Orthop Traumatol Surg Res 2019;105:781-7.

36. Fan H, Guo Z, Fu J, et al. Surgical management of pelvic Ewing's sarcoma in children and adolescents. Oncol Lett 2017;14:3917-26.

37. Pérez-Muñoz I, Grimer RJ, Spooner D, et al. Use of tissue expander in pelvic Ewing's sarcoma treated with radiotherapy. Eur J Surg Oncol 2014;40:197-201. 